\title{
Mechanisms of Dyspnea
}

\author{
Nausherwan K. Burki, MD, PhD, FCCP; and Lu-Yuan Lee, PhD
}

\begin{abstract}
The mechanisms and pathways of the sensation of dyspnea are incompletely understood, but recent studies have provided some clarification. Studies of patients with cord transection or polio, induced spinal anesthesia, or induced respiratory muscle paralysis indicate that activation of the respiratory muscles is not essential for the perception of dyspnea. Similarly, reflex chemostimulation by $\mathrm{CO}_{2}$ causes dyspnea, even in the presence of respiratory muscle paralysis or cord transection, indicating that reflex chemoreceptor stimulation per se is dyspnogenic. Sensory afferents in the vagus nerves have been considered to be closely associated with dyspnea, but the data were conflicting. However, recent studies have provided evidence of pulmonary vagal C-fiber involvement in the genesis of dyspnea, and recent animal data provide a basis to reconcile differences in responses to various $\mathbf{C}$-fiber stimuli, based on the ganglionic origin of the $\mathbf{C}$ fibers. Brain imaging studies have provided information on central pathways subserving dyspnea: Dyspnea is associated with activation of the limbic system, especially the insular area. These findings permit a clearer understanding of the mechanisms of dyspnea: Afferent information from reflex stimulation of the peripheral sensors (chemoreceptors and/or vagal $\mathrm{C}$ fibers) is processed centrally in the limbic system and sensorimotor cortex and results in increased neural output to the respiratory muscles. A perturbation in the ventilatory response due to weakness, paralysis, or increased mechanical load generates afferent information from vagal receptors in the lungs (and possibly mechanoreceptors in the respiratory muscles) to the sensorimotor cortex and results in the sensation of dyspnea.

CHEST 2010; 138(5):1196-1201
\end{abstract}

Abbreviations: 5-HT3 = 5-hydroxytryptamine subtype 3; NTS = nucleus tractus solitarius; TRPV1 = transient receptor potential vanilloid type 1

D yspnea, or shortness of breath, is perhaps the most common accompaniment of lung disease. The mechanism(s) and pathways of this sensation remain unclear, but recent animal and human studies have shed some light on this aspect of dyspnea.

Because of the nature of dyspnea, a sensation that can only be properly assessed in awake humans, studies of neural pathways, peripheral sensors, and

Manuscript received February 24, 2010; revision accepted June 21, 2010.

Affiliations: From the Division of Pulmonary and Critical Care (Dr Burki), University of Connecticut Health Center, Farmington, CT; and the Department of Physiology (Dr Lee), University of Kentucky Medical Center, Lexington, KY.

Funding/Support: This work was supported by the National Institutes of Health [Grant HL-65486].

Correspondence to: Nausherwan K. Burki, MD, PhD, FCCP, University of Connecticut Health Center, Pulmonary MedicineMC 1321, 263 Farmington Ave, Farmington, CT 06030; e-mail: nburki@uchc.edu

(C) 2010 American College of Chest Physicians. Reproduction of this article is prohibited without written permission from the American College of Chest Physicians (http://www.chestpubs.org/ site/misc/reprints.xhtml).

DOI: 10.1378/chest.10-0534 central mechanisms are difficult and progress has been slow. It is generally accepted that dyspnea involves central, peripheral (chest wall and lung receptors), and chemoreceptor mechanisms. ${ }^{1-3}$ Research in this field has consisted of studies of dyspnea or breathlessness in patients and normal subjects, as well as studies of related respiratory sensations, including the sensation of breath holding, the detection and perception of added respiratory loads, awareness of ventilation, and the ability to detect changes in $\mathrm{PCO}_{2}$ and $\mathrm{PO}_{2}$.

\section{The Language of Dyspnea}

Dyspnea has been distinguished from breathlessness in normal subjects, such as that induced by exercise, ${ }^{2}$ but it is unclear whether dyspnea refers to several different sensations or one sensation expressed differently. ${ }^{4}$ It has been suggested that the sensation of "air hunger" is related to the stimulation of chemoreceptors, whereas the sensation of an "unpleasant urge to breathe" may reflect central respiratory motor command, ${ }^{5,6}$ although distinctions 
between the sensations based on verbal descriptors are by no means clear. ${ }^{7}$

\section{PERIPHERAL RECEPTORS}

\section{Chest Wall Mechanoreceptors}

Muscle spindles and tendon organs in the respiratory muscles act as mechanoreceptors. They sense muscle tension and contraction and are innervated via the anterior horn cells of the spinal motor neurons and project to the somatosensory cortex. The diaphragms are richly supplied with tendon organs but have few spindle cells; they are innervated by the phrenic nerves (Fig 1). The role of these chest wall and diaphragm mechanoreceptors in dyspnea has been examined in studies after transection or block of the spinal cord.

Spinal anesthesia to $\mathrm{T} 1$ revealed no effects on the sensation of $\mathrm{CO}_{2}$ rebreathing, breath holding, or load-detection ability. ${ }^{8}$ In high-level (C1-C2) quadriplegics (ie, with denervation of both chest wall and diaphragm), ${ }^{9}$ the ability to detect lung volume change was still present, suggesting that pulmonary afferent information via the vagus nerves is perceived in the sensory cortex. Similarly, in a patient with spinal cord transection at C3, the ability to detect added resistive loads was the same as in a group of normal subjects. ${ }^{10}$ In summary, spinal cord block or transection does not prevent the ability to detect lung volume change or alter the sensations induced by an increase in $\mathrm{PCO}_{2}$, breath holding, or added respiratory loads.

Chest wall vibration has been studied to evaluate the role of mechanoreceptors. In-phase vibration of the chest wall (ie, vibration of inspiratory muscles during inspiration and expiratory muscles during expiration) results in a reduction in dyspnea induced by hypercapnia and resistive loading in normal subjects and patients with COPD, whereas out-of-phase vibration increases dyspnea. ${ }^{11}$ These results indicate that chest wall mechanoreceptors innervated via the spinal neurons have an important modifying effect on dyspnea, but respiratory muscle activity does not appear to be essential to the perception of dyspnea (see "Chemoreceptors").

\section{Chemoreceptors}

In normal subjects, the induction of hypercapnia or severe hypoxemia causes breathlessness. However, patients with hypercapnia and/or hypoxemia are not invariably dyspneic. The preponderance of evidence indicates that hypercapnia can induce breathlessness in the presence of effective denervation at $\mathrm{Cl}$, and hypercapnia can be sensed in the presence of cord transection at $\mathrm{C} 1 .^{5}$

It is important to note that in these studies the afferent pathways from airway sensory nerves via the vagus nerves were intact. In normal subjects and patients with lung disease voluntary hyperpnea to match reflex $\mathrm{CO}_{2}$-induced hyperpnea causes little or no breathlessness ${ }^{12}$; thus breathlessness related to hypercapnia appears to be dependent on the level of effective reflex chemostimulation.

The first studies of the effects of induced neuromuscular paralysis on respiratory sensation by Campbell and colleagues ${ }^{13}$ reported an absence of the dyspneic sensation during breath holding and hypercapnia after curare-induced respiratory muscle paralysis. However, subsequent studies ${ }^{6,14}$ found that dyspnea induced by hypercapnia is preserved following total neuromuscular blockade. These studies do not explain whether the source of the $\mathrm{CO}_{2}$-induced dyspnea lies in the peripheral or central chemoreceptors. Another possible source could be the bronchopulmonary vagal $\mathrm{C}$ fibers, which contain acid-sensing ion channels. ${ }^{15}$ In animals, $\mathrm{CO}_{2}$ stimulates bronchopulmonary vagal C-fiber afferents in the presence of inflammation, ${ }^{15}$ and it is possible that stimulation of these receptors by increased $\mathrm{CO}_{2}$ provides a signal for dyspnea.

The induction of acute hypoxia in normal subjects during exercise ${ }^{16}$ appears to increase the intensity of breathlessness in the absence of any specific effect on ventilation. During high-altitude hypoxia the intensity of exercise-induced breathlessness appears to be primarily related to the level of reflexly stimulated ventilation rather than to the level of hypoxia per se. ${ }^{17}$ In patients with dyspnea with chronic airways obstruction, however, it is unclear whether exercise-induced breathlessness is ameliorated with supplemental oxygen. ${ }^{18}$

Thus, the weight of current evidence suggests that hypercapnia is dyspnogenic in normal subjects and is dependent on the level of reflex stimulation of the respiratory centers; the source of the dyspnogenic signal, whether from the peripheral chemoreceptors, vagal $\mathrm{C}$ fibers, or central chemoreceptors, is unclear. Whether hypoxia is dyspnogenic per se remains uncertain.

\section{Lung Receptors}

Sensory information arising from the lungs is transmitted by the vagus nerves to the brainstem (Fig 2). These nerves consist of myelinated and unmyelinated fibers and the latter conduct $>75 \%$ of the afferent neural traffic in the vagus nerves. ${ }^{19}$ Sensory receptors in the lungs consist of rapidly adapting receptors, slowly adapting receptors, and polymodal $A \delta$-fibers in the large airways (the latter primarily in the larynx and trachea), all innervated by myelinated fibers of the vagus nerve,,$^{20,21}$ and unmyelinated vagal $C$ fibers, present in the entire respiratory tract.

The rapidly adapting receptors and slowly adapting receptors are involved primarily in pulmonary stretch 


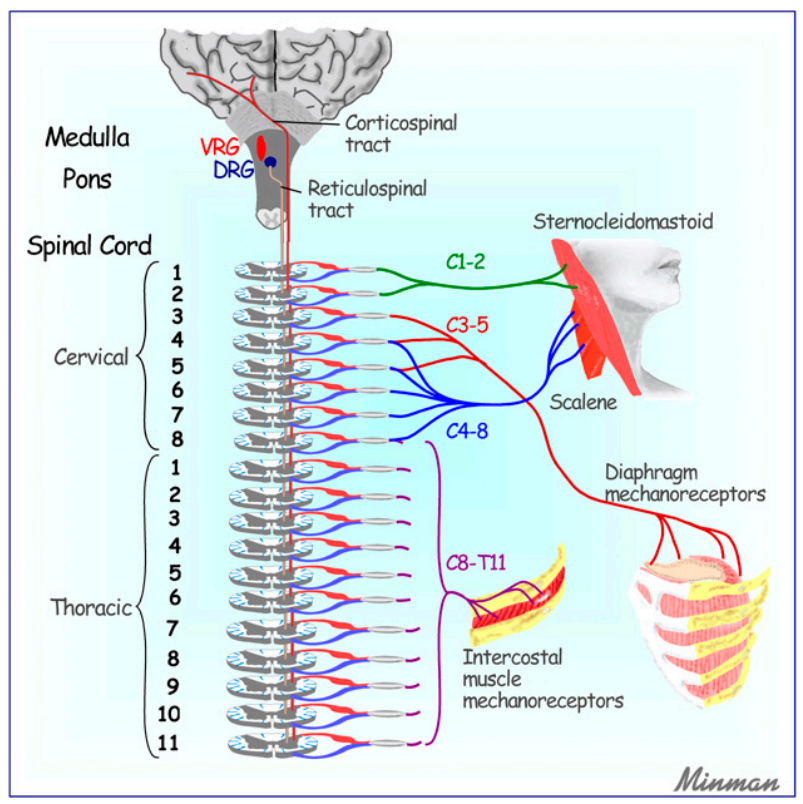

FIGURE 1. Schematic representation of afferent pathways from respiratory muscle mechanoreceptors to the $\mathrm{CNS}$. DRG $=$ dorsal respiratory group; $\mathrm{VRG}=$ ventral respiratory group.

and cough reflexes, modulating airway caliber and ventilatory pattern ${ }^{20}$; although they do not appear to play a major role in the genesis of dyspnea, the afferent information on lung volume changes they provide to the respiratory centers permits awareness of the level of ventilation and the "stretch" occurring in the lungs, which may be an essential part of the overall sensation of dyspnea.

Unmyelinated C fibers have been postulated as a possible source of dyspnea for many decades. ${ }^{22}$ Studies in humans ${ }^{23,24}$ have shown that the dyspneic sensation is decreased by vagal blockade or section, implicating the vagal nerves in this sensation. On the other hand, studies using chemical stimuli to the $\mathrm{C}$ fibers have given conflicting results. Capsaicin is known to stimulate transient receptor potential vanilloid type 1 (TRPV1) receptors expressed on C fibers..$^{20,25}$ After intravenous capsaicin injection, Winning et al ${ }^{26}$ noted a sensation of "raw, burning" feeling; no subject reported feeling breathless. These sensations were blocked by prior inhalation of anesthetic aerosol. Inhaled capsaicin induces cough ${ }^{25}$ but has not been documented to have any dyspnogenic effect. Phenyldiguanide is a selective 5-hydroxytryptamine subtype 3 (5-HT3) receptor agonist that can lead to stimulation of pulmonary $\mathrm{C}$ fibers. ${ }^{21}$ However, studies with phenyldiguanide ${ }^{27}$ have not reported any breathlessness. Finally, lobeline has been believed to stimulate vagal C fibers ${ }^{27}$; however, IV injection of lobeline in humans produces cough and sensations of respiratory discomfort referred to the throat and upper chest, 28 but sensations of breathlessness are not believed to be associated with lobeline stimulation of $\mathrm{C}$ fibers. ${ }^{29}$

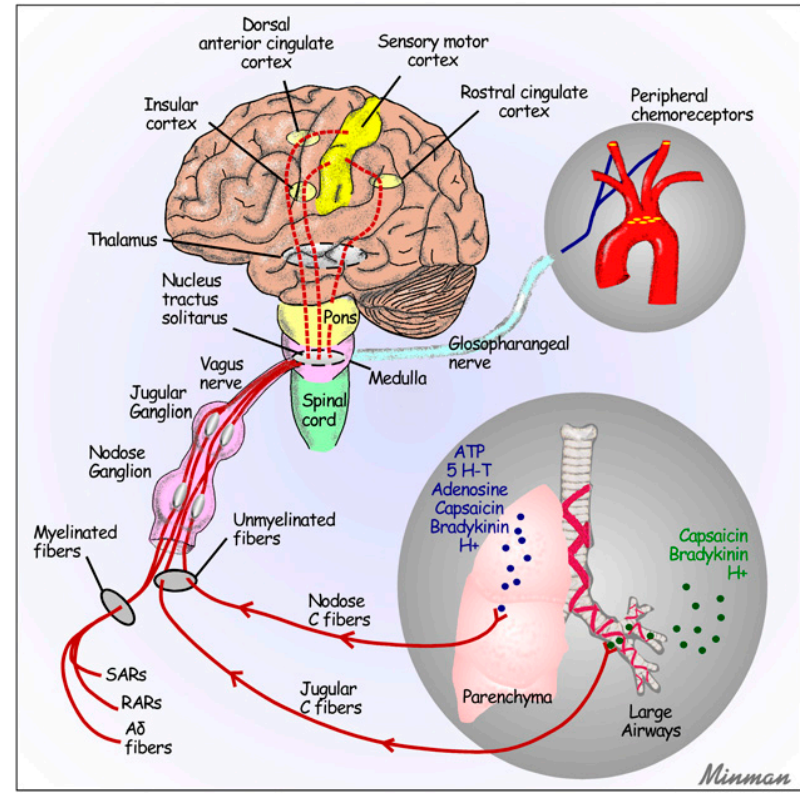

FIGURE 2. Schematic representation of afferent pathways of dyspnea from vagal receptors and peripheral chemoreceptors to the CNS. The precise pathways from the nucleus tractus solitarius to the limbic system and cortex are not clearly delineated and, hence, are shown as broken lines. RAR = rapidly adapting receptor; $\mathrm{SAR}=$ slowly adapting receptor.

In contrast, in a series of human studies ${ }^{30-32}$ we have shown that IV adenosine is dyspnogenic but does not cause coughing or bronchoconstriction. This dyspnogenic effect is increased in asthma ${ }^{31}$ and is attenuated by inhaled lidocaine ${ }^{32}$ or pretreatment with theophylline. These studies and previous animal data ${ }^{33,34}$ indicate that it is very likely that adenosine exerts its dyspnogenic effect by activating vagal $\mathrm{C}$ fibers by its action on adenosine $\mathrm{Al}$ receptors and possibly A2 receptors.

The reason for these apparent differences in the effects of various substances known to act on airway $\mathrm{C}$ fibers, and the fact that only adenosine appears to be specifically dyspnogenic, may be explained by recent animal studies of vagal sensory fibers. ${ }^{20,21}$ The sensory terminals of the $\mathrm{C}$ fibers express a number of ligand- and voltage-gated ion channels and pharmacologic receptors; these include TRPV1, adenosine receptors, acid-sensing ion channels, 5-HT3, P2X3 purinoceptor, nicotinic acetylcholine receptors, and so forth. ${ }^{15,21,35}$ It has been shown in guinea pigs that $\mathrm{C}$ fibers arising from the jugular ganglion (neural crest) are primarily associated with the large airways (ie, extrapulmonary airways and large intrapulmonary bronchi), whereas $\mathrm{C}$ fibers deeper in the lungs (ie, the "pulmonary" C fibers or J receptors ${ }^{22}$ have cell bodies more often situated in the nodose ganglia. ${ }^{20,21}$ The activation profile of jugular $\mathrm{C}$ fibers is distinct from the nodose (placodal) $\mathrm{C}$ fibers.

Nodose C fibers are stimulated by adenosine (via A1 receptors and, in some studies, also A2a receptors), 
and purinergic agonists such as ATP (via P2X2,3 heteromeric receptors), as well as via 5-HT3 receptors, ${ }^{21,27,35}$ whereas the jugular $\mathrm{C}$ fibers are unaffected by these stimuli.

We have shown that intravenous adenosine is dyspnogenic in humans but does not cause any cough, ${ }^{30-32}$ and that this effect can be attenuated by pretreatment with inhaled lidocaine (which blocks airway nerves by inhibition of the sodium channel and interruption of action potential conduction) and by blockade by systemic theophylline, a known, nonselective adenosine receptor antagonist. ${ }^{36}$ Our data indicate a greater attenuation of the dyspnogenic effects of adenosine with systemic theophylline than inhaled lidocaine, supporting the concept of an effect on the nodose $\mathrm{C}$ fibers. ${ }^{36}$ These differences in activation profiles also probably explain differences between the effects of capsaicin and intravenous adenosine. First, inhaled capsaicin is probably preferentially deposited in the distribution of the jugular $\mathrm{C}$ fibers; in addition, since capsaicin acts on the TRPV-1 receptor ${ }^{27}$ but not on the adenosine receptors, it is possible that the dyspneic sensation is specifically related to activation of a subgroup of $\mathrm{C}$ fibers that express adenosine receptors. Although lobeline and phenyldiguanide have not been studied in terms of their effects on these two different C-fiber phenotypes, it is probable that their primary effects are on the jugular $\mathrm{C}$ fibers.

\section{Central Mechanisms}

How is information derived from the peripheral respiratory system translated into the sensation of dyspnea? Studies of related sensory modalities, such as the detection/perception of added respiratory loads, have provided some insights. The detection of an added respiratory load is likely when inspiratory muscle force exceeds $10 \%$ to $20 \%$ of the muscle force necessary for a normal unloaded inspiration. ${ }^{37}$ In patients with chronic lung disease and equivalent degrees of mechanical abnormality, those with dyspnea had a significantly greater central inspiratory neuromuscular drive than the patients without dyspnea; furthermore, the ventilatory response for a given level of central drive was significantly less in the patients with dyspnea, indicating that it is the perturbation between central neuromuscular drive and respiratory response (ie, ventilation) that is related to dyspnea. ${ }^{1}$

However, although respiratory muscle activity per se is not essential to the perception of dyspnea, chest wall mechanoreceptors, vagal C fibers, and chemoreceptors all play a fundamental role in dyspnea genesis. Because of the difficulties inherent in neuroanatomic studies in humans, little is known about central neural processing of afferent pulmonary information. Vagal
C fibers carrying afferent information from the peripheral sensors project to the nucleus tractus solitarius (NTS) in the medulla. ${ }^{38}$ Similarly, the putative central chemoreceptive areas project second-order neurons to the $\mathrm{NTS}^{3}$; indeed, NTS neurons are putative central chemoreceptors themselves and the NTS is considered a key relay site for all respiratory afferent signals to the higher centers. Signal processing at synapses in the NTS, which incorporates activity in local circuits and upstream efferent signals, determines the output of sensory information from the lungs and airways to all downstream synapses in the reflex pathways, including higher brain regions. ${ }^{38,39}$

Anatomic afferent input from the NTS to the thalamus has been documented in rats ${ }^{40}$ and in monkeys the thalamus is activated by vagus nerve afferents ${ }^{41} \mathrm{In}$ cats and rats, stimulation of the cervical vagus nerves results in activation of the somatosensory cortex ${ }^{42}$ and insular cortex. ${ }^{43}$ Thus, afferent information transmitted via the vagus to the NTS is believed to ascend by a thalamocortical pathway to the viscerosensory insular cortex. ${ }^{44}$ A direct connection between the NTS and the limbic system has also been suggested. ${ }^{45}$

In humans, studies of respiratory-related evoked potentials indicate that the forebrain is activated with inspiratory occlusion. ${ }^{46}$ However, many of the respiratory sensations studied may or may not be related to dyspnea. Indeed, divergent areas of the cortex are stimulated by different respiratory stimuli: Inspiratory loads affect the left inferior frontal gyrus, ${ }^{47}$ whereas expiratory loads affect the right lateral frontal gyrus ${ }^{48}$ and hypercapnia activates the middle frontal gyrus. ${ }^{49}$ Although these studies of different respiratory sensations have provided useful information, this may not be specific to dyspnea.

Banzett and colleagues, ${ }^{50}$ using functional brain imaging with PET scans, showed that the anterior insula was activated when air hunger was induced by restricting tidal volume. ${ }^{51}$ Neural activation occurred in the right anterior insula, the cerebellar vermis, and the medial pons when respiratory discomfort was induced by external resistive loading. ${ }^{52}$

Additional studies by von Leupoldt and colleagues ${ }^{53,54}$ and Schön and colleagues ${ }^{55}$ using functional MRI confirm that induced dyspnea is associated with neuronal activations in the right anterior insula and in the right amygdala, and the perception of dyspnea and pain was blunted with neurologic lesions in this area. ${ }^{55}$

Thus, currently available information permits a general understanding of the neural mechanisms of dyspnea (Fig 2). The sensation appears to have two primary peripheral sensors-chemoreceptors and vagal $\mathrm{C}$ fibers; the chemoreceptors probably include the aortic and carotid bodies and/or vagal $\mathrm{C}$ fibers. Additional afferent information is provided by chest wall mechanoreceptors and vagal stretch receptors. 
Afferent neural information is conveyed to the NTS in the medulla and from there, probably via the thalamus, to the insular cortex and limbic system, especially the anterior insula, and the sensorimotor cortex. Thus, it can be speculated that dyspnea occurs when there is an increase above usual levels of reflex afferent information from the peripheral sensors, which is processed in the insula and cortical network and generates a neural output to the respiratory system; afferent feedback on the effects of this neural output (ie, pulmonary volume change, airflow, and ventilation), is provided by the pulmonary stretch and other receptors innervated by the vagal nerves and by chest wall mechanoreceptors. This information can be translated clinically: If central neural output does not produce the expected result (airflow or ventilation), either because of muscle paralysis or abnormal lung mechanics (eg, in COPD, asthma or restrictive lung disease), a sensation of dyspnea is generated. In asthma and COPD the relationship between inspiratory neural drive and ventilatory output, and therefore dyspnea, may worsen (increased functional residual capacity) on exercise and improves with bronchodilation. This assumes that the cortical centers have a pre-existing memory of "normal" afferent input and "normal" respiratory system response, in terms of effort required to achieve a given airflow or ventilation. The extent of the mismatch between the new afferent/efferent information and preexisting memory, ("a change in the relationship between central respiratory drive and output, ie, ventilation or effort")2 determines the intensity of dyspnea. Continuing research on the peripheral sensors and central neural pathways holds the promise of further clarifying mechanisms of this common sensation.

\section{ACKNOWLEDGMENTS}

Financial/nonfinancial disclosures: The authors have reported to CHEST that no potential conflicts of interest exist with any companies/organizations whose products or services may be discussed in this article.

\section{REFERENCES}

1. Burki NK. Breathlessness and mouth occlusion pressure in patients with chronic obstruction of the airways. Chest. 1979;76(5):527-531.

2. Burki NK. Dyspnea. Clin Chest Med. 1980;1(1):47-55.

3. Buchanan GF, Richerson GB. Role of chemoreceptors in mediating dyspnea. Respir Physiol Neurobiol. 2009;167(1):9-19.

4. Elliott MW, Adams L, Cockcroft A, MacRae KD, Murphy K, Guz A. The language of breathlessness. Use of verbal descriptors by patients with cardiopulmonary disease. Am Rev Respir Dis. 1991;144(4):826-832.

5. Banzett RB, Lansing RW, Reid MB, Adams L, Brown R. 'Air hunger' arising from increased PCO2 in mechanically ventilated quadriplegics. Respir Physiol. 1989;76(1):53-67.
6. Banzett RB, Lansing RW, Brown R, et al. 'Air hunger' from increased PCO2 persists after complete neuromuscular block in humans. Respir Physiol. 1990;81(1):1-17.

7. Ambrosino N, Serradori M. Determining the cause of dyspnoea: linguistic and biological descriptors. Chron Respir Dis. 2006;3(3):117-122

8. Eisele J, Trenchard D, Burki N, Guz A. The effect of chest wall block on respiratory sensation and control in man. Clin Sci. 1968;35(1):23-33.

9. Banzett RB, Lansing RW, Brown R. High-level quadriplegics perceive lung volume change. J Appl Physiol. 1987;62(2): 567-573.

10. Noble MIM, Frankel HL, Else W, Guz A. The ability of man to detect added resistive loads to breathing. Clin Sci. 1971;41(3):285-287.

11. Sibuya M, Yamada M, Kanamaru A, et al. Effect of chest wall vibration on dyspnea in patients with chronic respiratory disease. Am J Respir Crit Care Med. 1994;149(5): 1235-1240.

12. Adams L, Lane R, Shea SA, Cockcroft A, Guz A. Breathlessness during different forms of ventilatory stimulation: a study of mechanisms in normal subjects and respiratory patients. Clin Sci (Lond). 1985;69(6):663-672.

13. Campbell EJ, Godfrey S, Clark TJ, Freedman S, Norman J. The effect of muscular paralysis induced by tubocurarine on the duration and sensation of breath-holding during hypercapnia. Clin Sci. 1969;36(2):323-328

14. Gandevia SC, Killian K, McKenzie DK, et al. Respiratory sensations, cardiovascular control, kinaesthesia and transcranial stimulation during paralysis in humans. J Physiol. 1993;470: 85-107.

15. Lin R-L, Gu Q, Lin Y-S, Lee L-Y. Stimulatory effect of $\mathrm{CO}_{2}$ on vagal bronchopulmonary $\mathrm{C}$-fiber afferents during airway inflammation. J Appl Physiol. 2005;99(5):1704-1711.

16. Chronos N, Adams L, Guz A. Effect of hyperoxia and hypoxia on exercise-induced breathlessness in normal subjects. Clin Sci (Lond). 1988;74(5):531-537.

17. Burki NK, McConnell JW, Ayub M, Liles RM. Effects of acute prolonged exposure to high-altitude hypoxia on exercise-induced breathlessness. Clin Sci (Lond). 1999;96(4): 327-333.

18. Swinburn CR, Wakefield JM, Jones PW. Relationship between ventilation and breathlessness during exercise in chronic obstructive airways disease is not altered by prevention of hypoxaemia. Clin Sci (Lond). 1984;67(5):515-519.

19. Jammes Y, Fornaris E, Mei N, Barrat E. Afferent and efferent components of the bronchial vagal branches in cats. J Auton Nerv Syst. 1982;5(2):165-176.

20. Chou YL, Scarupa MD, Mori N, Canning BJ. Differential effects of airway afferent nerve subtypes on cough and respiration in anesthetized guinea pigs. Am J Physiol Regul Integr Comp Physiol. 2008;295(5):R1572-R1584.

21. Undem BJ, Nassenstein C. Airway nerves and dyspnea associated with inflammatory airway disease. Respir Physiol Neurobiol. 2009; 167(1):36-44.

22. Paintal AS. Mechanism of stimulation of type J pulmonary receptors. J Physiol. 1969;203(3):511-532.

23. Guz A, Noble MIM, Eisele JH. Experimental results of vagal block in cardiopulmonary disease. In: Porter R, ed. Breathing. Hering-Breuer Centenary Symposium. London, England: J \& A Churchill; 1970:315-329.

24. Davies SF, McQuaid KR, Iber C, et al. Extreme dyspnea from unilateral pulmonary venous obstruction. Demonstration of a vagal mechanism and relief by right vagotomy. Am Rev Respir Dis. 1987;136(1):184-188.

25. Dicpinigaitis PV. Experimentally induced cough. Pulm Pharmacol Ther. 2007;20(4):319-324. 
26. Winning AJ, Hamilton RD, Shea SA, Guz A. Respiratory and cardiovascular effects of central and peripheral intravenous injections of capsaicin in man: evidence for pulmonary chemosensitivity. Clin Sci (Lond). 1986;71(5): 519-526.

27. Jain SK, Subramanian S, Julka DB, Guz A. Search for evidence of lung chemoreflexes in man: study of respiratory and circulatory effects of phenyldiguanide and lobeline. Clin Sci. $1972 ; 42(2): 163-177$.

28. Gandevia SC, Butler JE, Taylor JL, Crawford MR. Absence of viscerosomatic inhibition with injections of lobeline designed to activate human pulmonary C fibres. J Physiol. 1998;511 (pt 1):289-300.

29. Butler JE, Anand A, Crawford MR, et al. Changes in respiratory sensations induced by lobeline after human bilateral lung transplantation. J Physiol. 2001;534(pt 2):583-593.

30. Burki NK, Dale WJ, Lee L-Y. Intravenous adenosine and dyspnea in humans. J Appl Physiol. 2005;98(1):180-185.

31. Burki NK, Alam M, Lee LY. The pulmonary effects of intravenous adenosine in asthmatic subjects. Respir Res. 2006;7:139.

32. Burki NK, Sheatt M, Lee L-Y. Effects of airway anesthesia on dyspnea and ventilatory response to intravenous injection of adenosine in healthy human subjects. Pulm Pharmacol Ther. 2008;21(1):208-213.

33. Hong JL, Ho CY, Kwong K, Lee LY. Activation of pulmonary $\mathrm{C}$ fibres by adenosine in anaesthetized rats: role of adenosine A1 receptors. J Physiol. 1998;508(Pt 1):109-118.

34. Gu Q, Ruan T, Hong JL, Burki N, Lee LY. Hypersensitivity of pulmonary $\mathrm{C}$ fibers induced by adenosine in anesthetized rats. J Appl Physiol. 2003;95(3):1315-1324.

35. Lee LY, Burki NK, Gerhardstein DC, Gu Q, Kou YR, Xu J. Airway irritation and cough evoked by inhaled cigarette smoke: role of neuronal nicotinic acetylcholine receptors. Pulm Pharmacol Ther. 2007;20(4):355-364.

36. Burki NK, Lee L-Y. Blockade of airway sensory nerves and dyspnea in humans. Pulm Pharmacol Ther. 2010;23(4): 279-282.

37. Burki NK. Detection of added respiratory loads in patients with restrictive lung disease. Am Rev Respir Dis. 1985;132(6): 1210-1213.

38. Bonham AC, Chen CY, Sekizawa S, Joad JP. Plasticity in the nucleus tractus solitarius and its influence on lung and airway reflexes. J Appl Physiol. 2006;101(1):322-327.

39. Swartz JB, Weinreich D. Influence of vagotomy on monosynaptic transmission at second-order nucleus tractus solitarius synapses. J Neurophysiol. 2009;102(5):2846-2855.

40. Ruggiero DA, Anwar S, Kim J, Glickstein SB. Visceral afferent pathways to the thalamus and olfactory tubercle: behavioral implications. Brain Res. 1998;799(1):159-171.
41. Ito S, Craig AD. Striatal projections of the vagal-responsive region of the thalamic parafascicular nucleus in macaque monkeys. J Comp Neurol. 2008;506(2):301-327.

42. Ito $S$, Craig AD. Vagal input to lateral area $3 \mathrm{a}$ in cat cortex. J Neurophysiol. 2003;90(1):143-154.

43. Ito $\mathrm{S}$. Electrophysiological evidence for projections of myelinated and non-myelinated primary vagal afferents to the rat insular cortex. Neurosci Lett. 1994;179(1-2):29-32.

44. Saper CB. The central autonomic nervous system: conscious visceral perception and autonomic pattern generation. Ann Rev Neurosci. 2002;25:433-469.

45. Davenport PW, Vovk A. Cortical and subcortical central neural pathways in respiratory sensations. Respir Physiol Neurobiol. 2009;167(1):72-86.

46. Davenport PW, Friedman WA, Thompson FJ, Franzén O. Respiratory-related cortical potentials evoked by inspiratory occlusion in humans. J Appl Physiol. 1986;60(6):1843-1848.

47. Macey KE, Macey PM, Woo MA, et al. Inspiratory loading elicits aberrant fMRI signal changes in obstructive sleep apnea. Respir Physiol Neurobiol. 2006;151(1):44-60.

48. Macey PM, Macey KE, Henderson LA, et al. Functional magnetic resonance imaging responses to expiratory loading in obstructive sleep apnea. Respir Physiol Neurobiol. 2003;138(2-3): 275-290.

49. Brannan S, Liotti M, Egan G, et al. Neuroimaging of cerebral activations and deactivations associated with hypercapnia and hunger for air. Proc Natl Acad Sci U S A. 2001;98(4): 2029-2034.

50. Banzett RB, Mulnier HE, Murphy K, Rosen SD, Wise RJ, Adams L. Breathlessness in humans activates insular cortex. Neuroreport. 2000;11(10):2117-2120.

51. Evans KC, Banzett RB, Adams L, McKay L, Frackowiak RS, Corfield DR. BOLD fMRI identifies limbic, paralimbic, and cerebellar activation during air hunger. J Neurophysiol. 2002;88(3):1500-1511.

52. Peiffer C, Poline JB, Thivard L, Aubier M, Samson Y. Neural substrates for the perception of acutely induced dyspnea. Am J Respir Crit Care Med. 2001;163(4):951-957.

53. von Leupoldt A, Sommer T, Kegat S, et al. The unpleasantness of perceived dyspnea is processed in the anterior insula and amygdala. Am J Respir Crit Care Med. 2008;177(9): 1026-1032.

54. von Leupoldt A, Sommer T, Kegat S, et al. Down-regulation of insular cortex responses to dyspnea and pain in asthma. Am J Respir Crit Care Med. 2009;180(3):232-238.

55. Schön D, Rosenkranz M, Regelsberger J, Dahme B, Büchel C, von Leupoldt A. Reduced perception of dyspnea and pain after right insular cortex lesions. Am J Respir Crit Care Med. 2008;178(11):1173-1179. 